\title{
Improved molecular detection of Babesia infections in animals using a novel quantitative real-time PCR diagnostic assay targeting mitochondrial DNA
}

Barbara A. Qurollo*, Nikole R. Archer, Megan E. Schreeg, Henry S. Marr, Adam J. Birkenheuer, Kaitlin N. Haney, Brittany S. Thomas and Edward B. Breitschwerdt

\begin{abstract}
Background: Babesiosis is a protozoal, tick transmitted disease found worldwide in humans, wildlife and domesticated animals. Commonly used approaches to diagnose babesiosis include microscopic examination of peripheral blood smears, detection of circulating antibodies and PCR. To screen and differentiate canine Babesia infections many PCR assays amplify the $18 \mathrm{~S}$ rRNA gene. These sequences contain hypervariable regions flanked by highly conserved regions allowing for amplification of a broad-range of Babesia spp. However, differences in the 185 rRNA gene sequence of distantly related clades can make it difficult to design assays that will amplify all Babesia species while excluding the amplification of other eukaryotes. By targeting Babesia mitochondrial genome $(\mathrm{mtDNA})$, we designed a novel three primer qPCR with greater sensitivity and broader screening capabilities to diagnose and differentiate Babesia spp.

Methods: Using 13 Babesia mtDNA sequences, a region spanning two large subunit rRNA gene fragments (Isu5-Isu4) was aligned to design three primers for use in a GPCR assay (LSU qPCR) capable of amplifying a wide range of Babesia spp. Plasmid clones were generated and used as standards to determine efficiency, linear dynamic range and analytical sensitivity. Animals naturally infected with vector-borne pathogens were tested retrospectively and prospectively to determine relative clinical sensitivity and specificity by comparing the LSU qPCR to an established $18 \mathrm{~S}$ rDNA qPCR.

Results: The LSU qPCR efficiencies ranged between 92 and 100\% with the limit of detection at five copies/reaction. The assay did not amplify mammalian host or other vector-borne pathogen gDNA except Cytauxzoon felis (a feline protozoal pathogen). The LSU qPCR assay amplified 12 different Babesia. sp. and C. felis from 31/31 (100\%) archived samples, whereas the 18S qPCR amplified only 26/31 (83.9\%). By prospective analysis, 19/394 diagnostic accessions (4.8\%) were LSU qPCR positive, compared to 11/394 (2.8\%) 18S rDNA qPCR positive.

Conclusions: We have developed a more sensitive qPCR assay with a more expansive range of Babesia spp. detection by targeting a highly conserved region of mtDNA, when compared to an established $18 \mathrm{~S}$ qPCR.
\end{abstract}

Keywords: Canine babesiosis, Babesia, Mitochondrial DNA, Quantitative PCR

\footnotetext{
* Correspondence: baquroll@ncsu.edu

Vector-borne Disease Diagnostic Laboratory, Comparative Medicine Institute,

College of Veterinary Medicine, North Carolina State University, Raleigh, NC,

USA
} 


\section{Background}

Babesiosis is a protozoal, tick transmitted disease found worldwide in humans, wildlife and domesticated animals. Dogs can be infected with a wide range of Babesia spp., including B. gibsoni, B. vogeli, B. canis, B. rossi, B. conradae, B. microti-like (also referred to as "Theileria annae" or "B. vulpes") and several large un-named Babesia spp., designated "B. coco" [1-6]. Clinical signs of canine babesiosis include thrombocytopenia, anemia, splenomegaly, fever, and can result in death [7]. Methods of diagnosing Babesia infections include microscopic examination of peripheral blood smears, indirect immunofluorescent antibody test to detect circulating antibodies and polymerase chain reaction (PCR) to detect pathogen DNA. Gene targets that have been used to amplify Babesia DNA include $18 \mathrm{~S}$ ribosomal RNA, betatubulin, heat shock protein 70 ( $h s p 70)$, thrombospondin related adhesive protein gene (P18 or BgTRAP) and two internal transcribed spacers (ITS1 and ITS2) [8-14]. Amplifying evolutionarily conserved genes, essential for survival, are often reliable PCR targets for genus-specific screening assays; however, identifying highly conserved regions for primer annealing in close proximity to regions of sequence heterogeneity for species discrimination can be challenging, particularly when including more distant lineages of Babesia spp. To screen and differentiate canine Babesia infections, the Vector-Borne Disease Diagnostic Laboratory at North Carolina State University (VBDDL-NCSU) has utilized a quantitative real-time PCR (qPCR) assay designed to amplify a region of the evolutionarily conserved 18S rRNA gene [15]. Ribosomal DNA sequences contain hypervariable regions, which are frequently used for species-specific amplification and are flanked by highly conserved regions used for broad-range genus amplification. This effectively allows amplification and discrimination of most Babesia species. However, differences in the $18 \mathrm{~S}$ rRNA gene sequence of the more distantly related clades, which include $B$. conradae and B. microti-like parasites, make it difficult to design $18 \mathrm{~S}$ rDNA assays that will amplify all Babesia species while excluding the amplification of other eukaryotes. Therefore, diagnostic laboratories often design separate and specific PCR assays to amplify $B$. conradae and $B$. microti-like in dogs where these pathogens are suspected. Screening for a wide range of Babesia species using specific primers for each species creates challenges for high throughput testing and limits the ability of a laboratory to identify "new" species that might infect dogs or other domestic and wild animals. In this study, we set out to design a novel assay with greater sensitivity and broader screening capabilities while retaining the ability to differentiate Babesia spp. This goal was achieved by targeting the Babesia mitochondrial genome (mtDNA).
Like other Apicomplexa, Babesia mtDNA can be present in higher copy numbers than the chromosomal genome and contains evolutionarily conserved genes including cytochrome b (cytb), cyclooxygenase (cox) and large subunit ribosomal DNA (lsu) [16]. Improved sensitivity over the $18 \mathrm{~S}$ rDNA target has been demonstrated using mtDNA targets in several Apicomplexa PCR assays, including Babesia and Theileria spp. [17-22]. To the authors' knowledge this report describes the first single qPCR targeting Babesia mtDNA that amplifies a wide range of Babesia spp. We describe the development and validation of a Babesia genus-specific, three primer qPCR assay targeting the $l s u 5-l s u 4$ region of mtDNA. The diagnostic utility of this assay (LSU qPCR) was demonstrated through retrospective and prospective analysis by comparing the sensitivity and specificity to an established $18 \mathrm{~S}$ rDNA Babesia genus-specific qPCR using blood samples from uninfected and naturally-infected animals.

\section{Methods \\ Samples}

Samples of ethylenediamine tetraacetic acid (EDTA)-anticoagulated whole blood specimens from various host animals submitted to the VBDDL-NCSU for research or diagnostic testing were used to test the sensitivity and specificity of this assay. Retrospective testing was performed on archived feline, bovine, canine, equine, and wildlife samples previously characterized as containing Babesia spp. $(n=31)$ to assess sensitivity, and samples containing a different vector-borne pathogen $(n=13)$ or samples from uninfected animals $(n=4)$ were used to assess specificity. Archived DNA samples were previously characterized as uninfected or infected using species-specific PCRs or PCR amplification and sequence analysis of the V4 hypervariable region of the Babesia 18S rRNA gene [8]. Six of the characterized samples were from previously published studies and included a $B$. rossi sample, three $B$. conradae samples and two $B$. microti-like samples from grey and red foxes [23-25]. Samples containing non-Babesia vector-borne pathogens were confirmed by PCR amplification and sequencing by the VBDDL-NCSU using species-specific gene targets and included Anaplasma platys, A. phagocytophilum, Bartonella henselae, Cytauxzoon felis, Ehrlichia canis, E. ewingii, Hepatozoon americanum, H. canis, Leishmania infantum, Mycoplasma hemocanis, Neorickettsia risticii, Rickettsia rickettsii, Theileria equi and Trypanosoma cruzi. Prospective testing was performed on canine samples submitted between July 1, 2015 and August 28, 2015 for vector-borne disease testing $(n=394)$.

\section{Primers}

To design primers better able to detect DNA from known and emerging Babesia spp., alignments were made between a wide range of Babesia mtDNA sequences. A 
region spanning two large subunit rRNA gene fragments (lsu5 and lsu4) conserved among Babesia spp. containing sequence heterogeneity, flanked by areas of high similarity, was identified as a potential new qPCR target (Fig. 1) [26-28]. To develop a new Babesia LSU qPCR (LSU qPCR), three primers ( 2 forward, 1 reverse; Table 1) were designed using an alignment of the following 13 Babesia mtDNA sequences: B. bovis (AB499088), B. bigemina (AB499085), B. caballi (AB499086), B. coco (KC207824), B. canis (KC207822), B. rossi (KC207823), B. vogeli (KC207825), B. conradae (KC207826), B. divergens (LK935355), B. gibsoni (AB499087), B. microti-type II (AB624354), B. microti-type IV (AB624356) and B. microti-like (KC207827) (Fig. 2). B-lsu-F and B-lsu-R2 were designed to amplify a $\sim 150$ bp product from all Babesia spp. in the alignment except B. microti or $B$. microti-like. Bmic-F was designed to amplify a $\sim 230 \mathrm{bp}$ product from $B$. microti or $B$. microti-like when used with B-lsu-R2 (Figs. 1, 2). For assay comparisons, an established Babesia genus 18S rDNA qPCR (18S qPCR), utilized by the VBDDL-NCSU for Babesia molecular diagnostic detection, was used to amplify a $\sim 200$ bp region of the Babesia 18S rRNA gene with Bcommon_F and Bcommon_R primers (Table 1). Established Babesia speciesspecific PCRs using primers designed to anneal to a hypervariable region of the $18 \mathrm{~S}$ rRNA gene and newly designed species-specific cox1 (a gene found on the mtDNA) primers were used to confirm Babesia species in LSU qPCR and 18S qPCR positive samples (Table 1). Initial amplicons generated in both the LSU qPCR and cox1 species-specific qPCRs from samples containing known Babesia spp. were sequenced to confirm primers amplified the correct target DNA for each Babesia species. Amplicons generated during prospective testing from the LSU-qPCR but not the $18 \mathrm{~S}$ qPCR assay (discordant results) were sequenced.

\section{DNA extraction and PCR conditions}

DNA extraction was performed on QIAsymphony ${ }^{\mathrm{SP}}$ (Qiagen, Hilden, Germany) with QIAsymphony ${ }^{\circ}$ DNA Mini Kit (192) (Qiagen) or Qiagen BioRobot ${ }^{\circ}$ M48 Robotic Workstation with MagAttract ${ }^{\circ}$ DNA Mini M48 kit (Qiagen) depending on the time of sample submission. DNA was stored at $-20{ }^{\circ} \mathrm{C}$ until PCR analysis. All PCR sample preparations were prepared in a biocontainment hood with UV light decontamination capabilities. The absence of PCR inhibitors was demonstrated by the amplification of GAPDH (glyceraldehyde-3-phosphate dehydrogenase) [8]. Amplification reactions for all PCRs contained $12.5 \mu \mathrm{l} \mathrm{SYBR}^{\circ}$ Green Supermix (Bio-Rad, Hercules, USA), $5 \mu$ l DNA template, primers at various concentrations (Table 2) and molecular grade water to a final volume of $25 \mu \mathrm{l}$. Thermocycler conditions were established based on several factors, which included using temperature cycles that could be run with other NCSU-VBDDL qPCR assays, recommendations by BioRad for use of $\mathrm{SYBR}^{\circ}$ Green Supermix, and calculated melting temperatures of newly designed primers. Furthermore, gradients for primer annealing temperatures and concentrations were performed to identify a combination

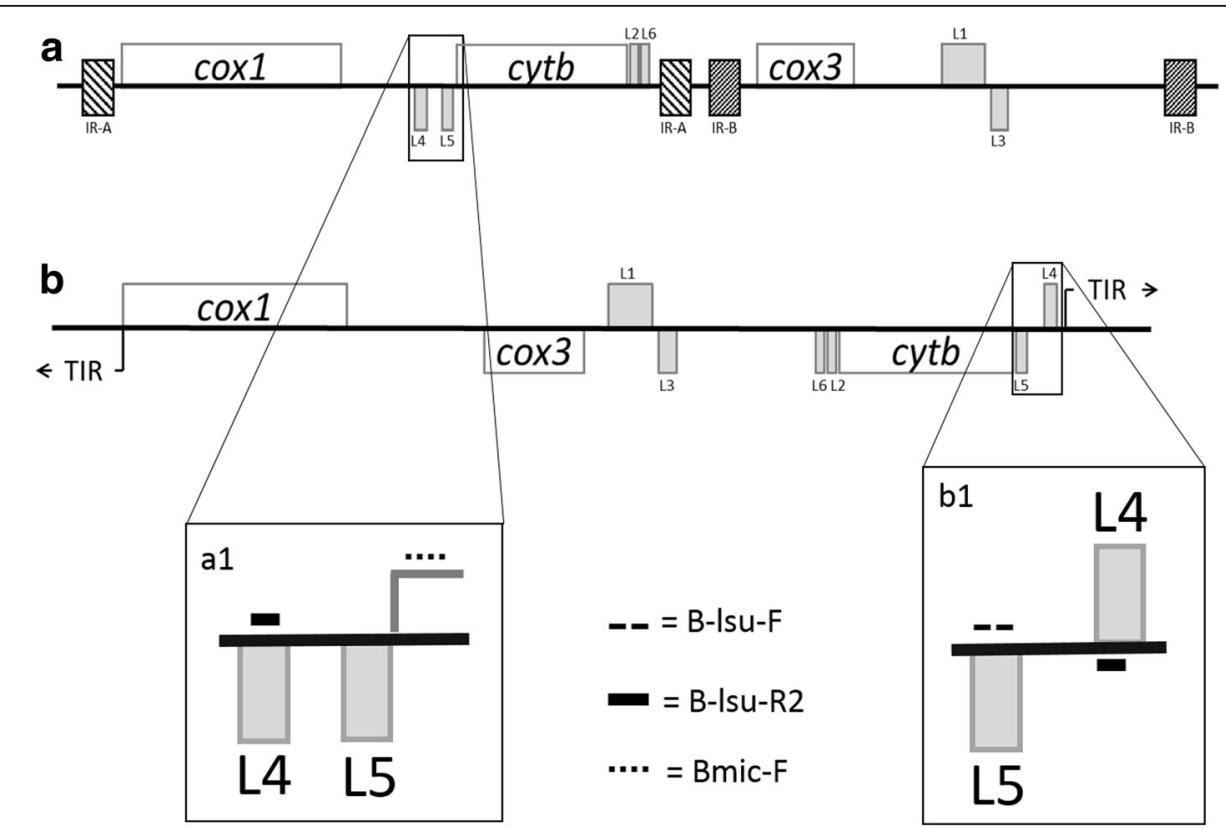

Fig. 1 Babesia LSU qPCR primers in relation to the mitochondrial DNA genome structure. a al Babesia microti (Type-I and Type II orientation) [27] and B. microti-like [28]; b b1 "typical" Piroplasmida [26] 
Table 1 Primer sequences for Babesia genus and species-specific PCRs

\begin{tabular}{|c|c|c|}
\hline Primer name & Gene target & Sequence $\left(5^{\prime}-3^{\prime}\right)$ \\
\hline B-Isu-F & Babesia Isu5-Isu4 & ACCTGTCAARTTCCTTCACTAAMTT \\
\hline B-Isu-R2 & Babesia Isu5-Isu4 & TCTTAACCCAACTCACGTACCA \\
\hline Bmic-F & B. microti-like Isu5-Isu4 & TTGCGATAGTAATAGATTTACTGC \\
\hline Bcommon-F & Babesia 18S rRNA & GCATTTGCGATGGACCATTCAAG \\
\hline Bcommon-R & Babesia 18S rRNA & CCTGTATTGTTATTTCTTGTCACTACCTC \\
\hline BMIC18-F & B. microti-like $18 \mathrm{~S}$ rRNA & CTGCTITATCATTAATTTCGCTTCCGAACG \\
\hline$B C V-F$ & B. vogeli $18 \mathrm{~S}$ rRNA & GTTCGAGTTTGCCATTCGTT \\
\hline$B C C-F$ & B. canis 185 rRNA & TTGCGTTGACGGTTTGACC \\
\hline BCO-F & B. COCO 185 rRNA & CCTITCTTTGCTTTGTCGC \\
\hline BGNC-F & B. gibsoni $18 \mathrm{~S}$ rRNA & ACTCGGCTACTTGCCTTGTC \\
\hline BAB722-R & Babesia 185 rRNA & ATGCCCCCAACCGTTCCTATTA \\
\hline BCV-cox1-F4 & B. vogeli cox 1 & TGCTATGAGTGGCGCAAATTTTG \\
\hline$B C V-\operatorname{cox} 1-R$ & B. vogeli cox 1 & CCATACAGTAGGTATCAATCTATCT \\
\hline BCC-Cox1-F2 & B. canis cox 1 & GTGCAATGAGTGGAGCAAATTTCA \\
\hline$B C C-\operatorname{cox} 1-R$ & B. canis cox 1 & CCATACAGTTGGTATTAATCTATCC \\
\hline BCO-COX1-F2 & B. $\operatorname{coco} \operatorname{cox} 1$ & TTGTAACTTCTGTITTACTTATGGTG \\
\hline BCO-cox1-R2 & B. $\operatorname{coco} \operatorname{cox} 1$ & AAAATAAGAATATAAACCTCAGGATGT \\
\hline BG-cox1-F & B. gibsoni cox 1 & CTTCAGCCAATAGCTTTCTGTTTG \\
\hline$B G-\operatorname{cox} 1-R$ & B. gibsoni cox1 & CCTGAGGCAAGTAAACCAAATAT \\
\hline
\end{tabular}

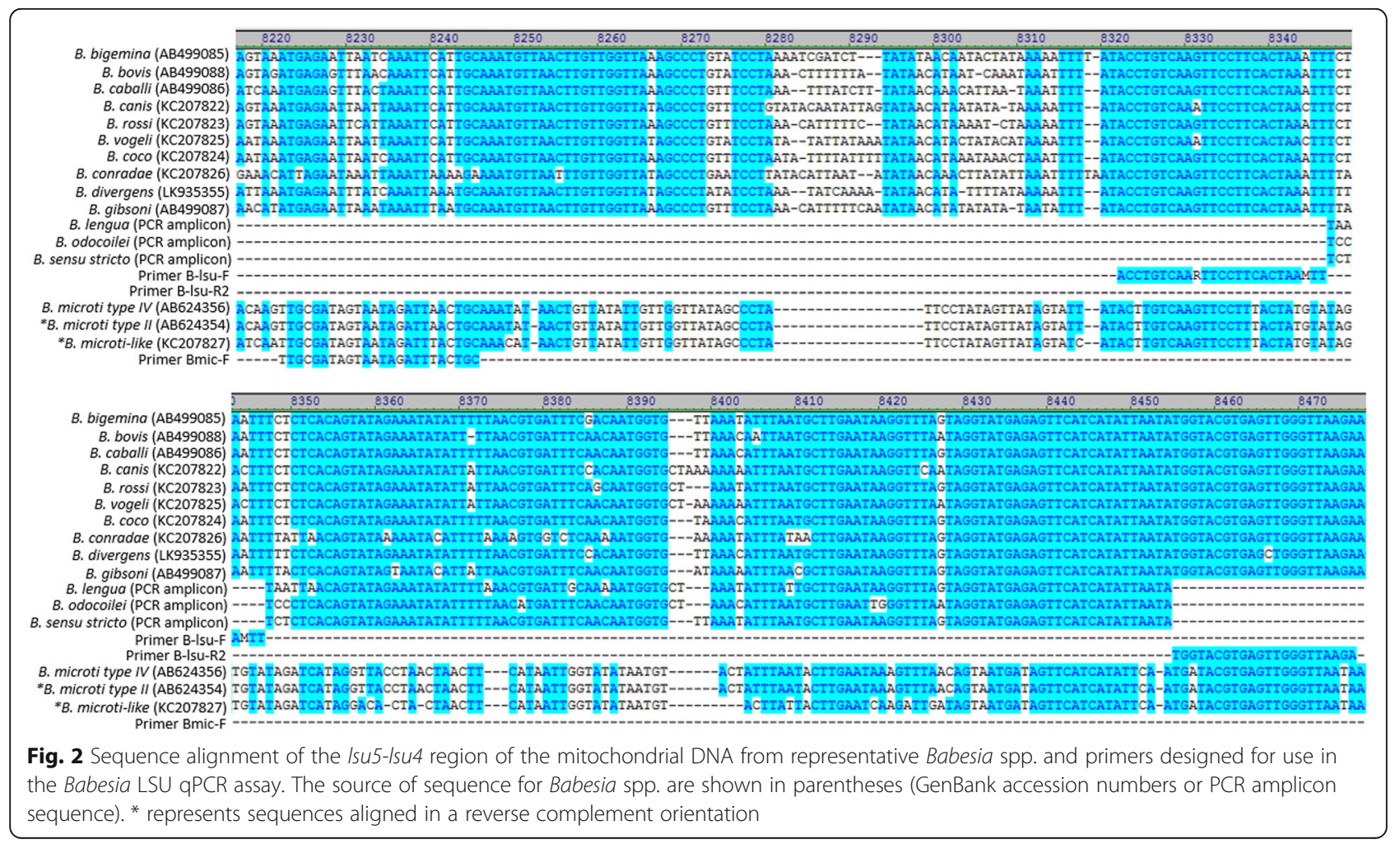


Table 2 Primer combinations and concentrations used for species of the genus Babesia and species-specific (sp-sp) PCRs

\begin{tabular}{ll}
\hline qPCR & Primer combination $(\mu \mathrm{M})$ \\
\hline Babesia genus LSU qPCR & B-Isu-F (0.6); B-Isu-R2 (0.6); Bmic-F (0.4) \\
Babesia genus 18S qPCR & Bcommon-F (0.4); Bcommon-R (0.4) \\
B. microti-like sp-sp 18S qPCR & BMIC18-F (0.8); BAB722 (0.8) \\
B. vogeli sp-sp 18S qPCR & BCV-F (0.4); BAB722 (0.4) \\
B. canis sp-sp 18S qPCR & BCC-F (0.4); BAB722 (0.4) \\
B. coco sp-sp 18S qPCR & BCO-F (0.4); BAB722 (0.4) \\
B. gibsoni sp-sp 18S qPCR & BGNC-F (0.4); BAB722 (0.4) \\
B. vogeli sp-sp cox1 qPCR & BCV-cox1-F4 (0.4); BCV-cox1-R (0.4) \\
B. canis sp-sp cox1 qPCR & BCC-cox1-F2 (0.4); BCC-cox1-R (0.4) \\
B. coco sp-sp cox1 qPCR & BCO-cox1-F2 (0.4); BCO-cox1-R2 (0.4) \\
B. gibsoni sp-sp cox1 qPCR & BG-cox1-F (0.4); BG-cox1-R (0.4) \\
\hline
\end{tabular}

that amplified target DNA efficiently but did not amplify nonspecific DNA. Thermocycler conditions consisted of an initial denaturation step at $98^{\circ} \mathrm{C}$ for $3 \mathrm{~min}$, followed by 40 cycles at $98{ }^{\circ} \mathrm{C}$ for $15 \mathrm{~s}, 60^{\circ} \mathrm{C}$ for $15 \mathrm{~s}$ (or $62{ }^{\circ} \mathrm{C}$ for $B$. microti-like $18 \mathrm{~S}$ species-specific qPCR), and $72{ }^{\circ} \mathrm{C}$ for $15 \mathrm{~s}$. Melting temperature $\left(T_{m}\right)$ measurements were made between 65 and $88{ }^{\circ} \mathrm{C}$ at $0.5 \mathrm{~s}$ intervals. All qPCRs included a positive control consisting of either a previously characterized Babesia-infected sample or Babesia plasmid DNA and negative controls including a no-template control consisting of filter-sterilized, molecular-grade water and uninfected dog or cat genomic DNA (gDNA). Newly extracted samples were tested with DNA extraction controls. PCR amplification was performed in a $\mathrm{C} 1000^{\mathrm{m}}$ Thermal Cycler (Bio-Rad) with CFX96 ${ }^{\text {tu }}$ Real-Time Detection System. Following PCR, amplicons were analyzed via the quantification cycle $\left(\mathrm{C}_{\mathrm{q}}\right)$, melt curve shape and $T_{m}$ difference. To validate amplicon size, several PCR products were visualized on a $2.0 \%$ agarose gel in $1 \times$ TAE with ethidium bromide staining alongside a DNA molecular size marker. Sequencing of products or plasmids was performed by GENEWIZ Inc. (Research Triangle Park, $\mathrm{NC}$ ) and alignments made with GenBank reference sequences using AlignX software (Vector NTI Suite 6.0, InforMax, Inc.)

\section{qPCR efficiency}

Plasmid clones, used as standards for efficiency and analytical sensitivity determination, were constructed using LSU qPCR amplicons from B. vogeli, and B. microti-like template DNA with pGEM-T Easy Vector System (Promega, Madison, WI) as recommended by the manufacturer. Plasmids were sequenced and inserts confirmed using M13R primers. Plasmid copy numbers were calculated assuming an average base pair weight of $650 \mathrm{Da}$ and Avogadro's number $\left(6.0221^{23}\right)$ using the following equation: copy number $=\left(\right.$ DNA ng amount $\times 6.02210^{23}$ molecules $/ \mathrm{mol}) /($ length of DNA in base pairs $\times 1 \times$ $\left.10^{9} \mathrm{ng} / \mathrm{g} \times 650 \mathrm{~g} / \mathrm{mol}\right)$. Duplicate, serial 10-fold dilutions in uninfected canine gDNA $(\sim 10-30 \mathrm{ng} / \mu \mathrm{l})$ resulted in $50-500,000$ copies/reaction of plasmid DNA, and standard curves of quantification cycle $\left(\mathrm{C}_{\mathrm{q}}\right)$ values were plotted against the logarithm of plasmid copy numbers/reaction. PCR efficiency was estimated through linear regression of the dilution curve $\left(10^{\wedge}(-1 /\right.$ slope $\left.\left.)-1\right) \times 100\right)$. Coefficients were calculated $\left(R^{2}\right)$ using Bio-Rad CFX Manager ${ }^{\text {rm }}$ software. Efficiency reactions were performed using both 2 and 3 primer reactions to establish any potential interference by a third primer.

\section{Analytical sensitivity and specificity}

Analytical sensitivity was determined by calculating the limit of detection (LOD), defined as the lowest concentration at which $95 \%$ of the positive samples were detected. Plasmids diluted in canine gDNA $(\sim 10-30 \mathrm{ng} / \mu \mathrm{l})$ to $1 \mathrm{copy} / \mu \mathrm{l}$ were added to reaction wells resulting in 3 and 5 copies/reaction. Twenty intra-assay replicates for each plasmid concentration were tested and $\mathrm{C}_{\mathrm{q}}$ ranges determined. All assays were performed using both 2 and 3 primer reactions to establish any potential interference by a third primer. Analytical specificity was evaluated retrospectively using gDNA $(\sim 10-30 \mathrm{ng} / \mu \mathrm{l})$ previously extracted from bovine, canine, equine and feline EDTAwhole blood specimens and tested by the VBDDL, determined to be either uninfected or infected with non-Babesia vector-borne pathogens.

\section{Clinical sensitivity and specificity}

To determine relative clinical sensitivity and specificity, the LSU qPCR was compared to an established Babesia $18 \mathrm{~S}$ qPCR diagnostic assay that has been used for over 12 years. Retrospective and prospective testing was performed. Retrospective analysis included 31 archived gDNA samples, previously characterized as positive with 12 different Babesia spp. including B. bovis, B. caballi, $B$. canis, B. rossi, B. vogeli, B. coco, B. conradae, $B$. gibsoni, B. lengau, B. microti-like, B. odocoilei, and two Babesia species in the Babesia (sensu stricto) clade, or $C$. felis. After amplification with the LSU qPCR, one of each of the 12-designated species from the retrospective sample set was sequenced and aligned with a reference sequence for species confirmation. Prospective analysis included 394 canine diagnostic specimens submitted to the VBDDL for testing using a comprehensive vectorborne disease PCR panel, or when specifically requested, Babesia PCR alone. All samples were simultaneously tested using the $18 \mathrm{~S}$ qPCR assay and the LSU qPCR assay. Prospective specimens were tested at the time of submission and all PCR positive results were speciated with additional, species-specific PCRs targeting $18 \mathrm{~S}$ rRNA or the $\operatorname{cox} 1$ gene. In addition, any discordant PCR 
positive amplicons from the prospective study were sequenced to confirm results and were retested in triplicate with both PCRs to account for the effect of Poisson distribution on samples with low template concentrations.

\section{Statistical analysis}

Relative sensitivity and specificity for the $18 \mathrm{~S}$ qPCR and LSU qPCR were determined by a $2 \times 2$ table, calculating an estimate of agreement relative to a non-reference standard, either the 18S qPCR or the LSU qPCR [29]. Positive percent agreement (PPA), representing relative sensitivity, was determined by the proportion of nonreference standard positive samples where the index assay is positive $[a /(a+c)]$, and negative percent agreement (NPA), representing relative specificity, was determined by the proportion of non-reference standard negative samples where the index test is negative $[d /(b+d)]$. Agreements and proportions were reported with their $95 \%$ confidence intervals $(95 \% \mathrm{CI})$, calculated by the modified Wald method [30, 31]. Confidence intervals were performed using GraphPad Software (La Jolla, California, USA).

\section{Results}

qPCR efficiency, analytical sensitivity and specificity

Amplicon size for each primer pair was visualized on an agarose gel and corresponded to the expected size of $\sim 150$ bp for most Babesia spp. and $\sim 230$ bp for $B$. microti-like. $T_{m}$ ranged from 76 to 77.5 . LSU qPCR efficiencies ranged from 92 to $100 \%$ with an $\mathrm{R}^{2}$ of 0.99 and a linear dynamic range of 50-500,000 copies/reaction of plasmid DNA (Table 3, Fig. 3). Results were comparable when using either two primers (Bmic-F with B-lsu-R2 for B. microti-like plasmid template or B-lsu-F with Blsu-R2 for $B$. vogeli plasmid template) or three primers (Bmic-F, B-lsu-F and B-lsu-R2) (Table 3). LODs were initially tested at 3 copies/well using 20 intra-assay replicates, with detection ranging from 60 to $90 \%$ (Table 3). When the LOD was repeated at 5 copies/well, all reactions showed $100 \%$ detection except the 3 primer B. microti-like reaction (95\% detection). Neither the LSU qPCR nor the $18 \mathrm{~S}$ qPCR amplified uninfected mammalian host DNA.
The LSU qPCR did not amplify non-Babesia vector-borne pathogens except for $C$. felis, and the $18 \mathrm{~S}$ qPCR amplified C. felis, H. canis and T. equi (Table 4).

\section{Clinical sensitivity and specificity}

Of the 31 archived, naturally-infected animal blood samples, previously characterized as containing 12 different Babesia spp. or C. felis, 31/31 (100\%) were LSU qPCR positive and 26/31 (83.9\%) were 18S qPCR positive (Table 4). The sequenced LSU qPCR amplicons from 9/ 12 Babesia species and C. felis were $100 \%$ identical with GenBank reference sequences. Babesia lengau, B. odocoilei and Babesia (sensu stricto) mtDNA reference sequences were not available in GenBank for comparison and were aligned with the lsu5-lsu4 region from other Babesia mtDNA sequences (Fig. 2). Of the 26 concordant samples, the average $\mathrm{C}_{\mathrm{q}}$ value difference between the two qPCRs $\left(\Delta \mathrm{C}_{\mathrm{q}}=18 \mathrm{~S} \mathrm{qPCR} \mathrm{C}_{\mathrm{q}}-\mathrm{LSU} \mathrm{qPCR} \mathrm{C}_{\mathrm{q}}\right)$ was 7.1. The LSU qPCR $\mathrm{C}_{\mathrm{q}}$ was less than the $18 \mathrm{~S} q \mathrm{qCR} \mathrm{C}_{\mathrm{q}}$ (representing earlier amplicon production) for $B$. bovis $\left(\Delta \mathrm{C}_{\mathrm{q}}=15.2\right)$, B. coco $\left(\Delta \mathrm{C}_{\mathrm{q}}=6.9\right.$ and 7.0), B. conradae $\left(\Delta \mathrm{C}_{\mathrm{q}}=13.5,14.5\right.$, and 19.3), B. microti-like $\left(\Delta \mathrm{C}_{\mathrm{q}}=8.0\right.$, 8.4, and 8.7), B. lengau $\left(\Delta \mathrm{C}_{\mathrm{q}}=20.2\right)$ and $C$. felis $\left(\Delta \mathrm{C}_{\mathrm{q}}=14.2\right.$ and 14.6) (Fig. 4). Babesia odocoilei was the only Babesia species in this sample set where the $18 \mathrm{~S}$ qPCR amplified DNA at a lower $C_{q}\left(\Delta C_{q}=-10.7,-12.1\right.$ and -7.35$)$ than the LSU qPCR.

Of the 394 canine diagnostic specimens submitted for vector-borne disease testing, 2.8\% (11/394; 95\% CI: 1.1$4.4 \%$ ) were Babesia-positive by the $18 \mathrm{~S}$ qPCR and $4.8 \%$ (19/394; 95\% CI: $3.1-7.5 \%)$ were positive by the LSU qPCR (Table 5). All but one of the positive samples were speciated using species-specific PCRs targeting the $18 \mathrm{~S}$ rRNA or cox1 gene (Table 6). The Babesia spp. that tested positive by both qPCR assays included $B$. canis $(n=2)$, B. vogeli $(n=2)$ and B. gibsoni $(n=7)$ (Table 6). Discordant results were obtained for 8 samples that were $18 \mathrm{~S}$ qPCR negative, but LSU qPCR positive, including B. coco $(n=2)$, B. gibsoni $(n=5)$ and B. microtilike $(n=1)$ (Table 6). All but one of the discordant samples were confirmed by cox 1 species-specific qPCRs and amplicon sequencing of the LSU qPCR product. Two

Table 3 The efficiency and analytical sensitivity for the Babesia LSU qPCR. The efficiency and analytical sensitivity were determined for the Babesia LSU qPCR using plasmids as template DNA run in 20 intra-assay replicates at 3 copies/well and 5 copies/well. Assays were run with all 3 primers (Bmic-F, B-Isu-F and B-Isu-R2) for both plasmids and each corresponding 2 primer reaction: Bmic-F with B-Isu-R2 for B. microti-like plasmid (pBMIC-LSU) and B-Isu-F with B-Isu-R2 for B. vogeli plasmid (pBCV-LSU)

\begin{tabular}{llllllll}
\hline Primers & Plasmid template & Eff $(\%)$ & $R^{2}$ & 3 c/well (\%) & Cq (range) & 5 c/well (\%) & Cq (range) \\
\hline 2 primers & pBMIC-LSU & 100 & 0.99 & 90 & $34.1-37.2$ & 100 & $33.5-37.5$ \\
3 primers & pBMIC-LSU & 95 & 0.99 & 70 & $33.6-37.3$ & 95 & $34.2-37.8$ \\
2 primers & pBCV-LSU & 94 & 0.99 & 60 & $37.1-39.9$ & 100 & $33.3-36.7$ \\
3 primers & pBCV-LSU & 92 & 0.99 & 60 & $36.8-39.2$ & 100 & $33-34.2$ \\
\hline
\end{tabular}

Abbreviations:Eff efficiency, C copies 

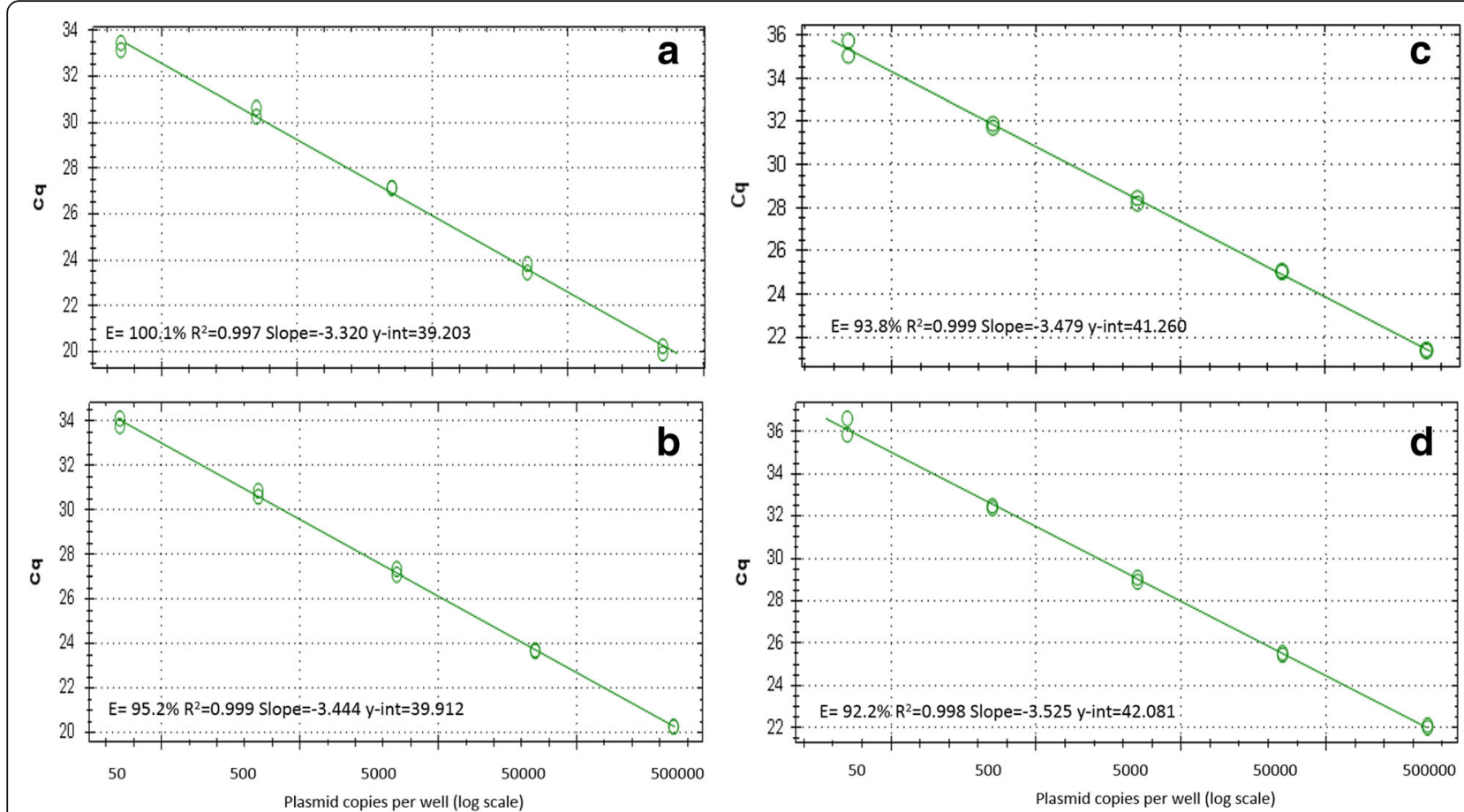

Fig. 3 Efficiency curves for the Babesia LSU qPCR using plasmids as template DNA. a B. microti-like plasmid (pBMIC-LSU) with 2 primers (Bmic_F and B-Isu-R2). b pBMIC-LSU with 3 primers (Bmic-F, B-Isu-F and B-Isu-R2). c B. vogeli plasmid (pBCV-LSU) with 2 primers (B-Isu-F and B-Isu-R2). d pBCV-LSU with 3 primers (Bmic-F, B-Isu-F and B-Isu-R2). Abbreviation: E, efficiency

of the discordant samples were also positive by $18 \mathrm{~S}$ species-specific qPCRs (Table 6). Of the discordant samples that were retested in triplicate with the LSU qPCR, 4 were positive in $3 / 3$ replicates, 2 were positive in $2 / 3$ replicates, 1 was positive in $1 / 3$ replicates and 1 was negative in $3 / 3$ replicates. For the $18 \mathrm{~S}$ qPCR triplicate retest, 7 discordant samples were negative again in $3 / 3$ replicates and 1 (B. gibsoni) was positive in $1 / 3$ replicates (Table 6).

Relative sensitivity and specificity between the $18 \mathrm{~S}$ qPCR and LSU qPCR were determined by calculating the PPA and NPA for each assay [29] (Table 7). When using the $18 \mathrm{~S}$ qPCR as a non-reference standard, the relative sensitivity (PPA) and specificity (NPA) of the LSU qPCR was 100\% (95\% CI: 69.9-100\%) and 98\% (95\% CI: 95.9-99.0\%), respectively. When using the LSU qPCR as a non-reference standard, the relative sensitivity (PPA) and specificity (NPA) for the $18 \mathrm{~S}$ qPCR was $58 \%$ (95\% CI: $36.2-76.9 \%)$ and 100\% (95\% CI: $98.8-100 \%)$, respectively.

\section{Discussion}

In this report, we describe the development and validation of a sensitive and specific broad-range molecular diagnostic assay for detecting Babesia infections using a three-primer qPCR assay targeting the mtDNA. Prior to validation of the LSU qPCR, the VBDDL utilized a qPCR targeting the $18 \mathrm{~S}$ rRNA gene, optimized to detect
Babesia species infective to dogs, which included $B$. canis, B. gibsoni, B. rossi and B. vogeli [15]. Since development of the $18 \mathrm{~S}$ qPCR assay, emerging Babesia species have been discovered to infect dogs, including $B$. conradae, $B$. microti-like and several large un-named Babesia spp., designated B. coco [5-7]. Furthermore, diagnostic laboratories, including NCSU-VBDDL, routinely test for emerging Babesia spp. in samples collected from other animals, such as wildlife. At high pathogen DNA quantities, the $18 \mathrm{~S}$ qPCR can amplify $18 \mathrm{~S}$ ribosomal DNA from these emerging species; however, amplification efficiency is poor with lower pathogen loads. Other Babesia diagnostic methods include testing with multiple, individual, species-specific PCR assays, reverse line blotting, or nested PCRrestriction fragment length polymorphism analysis. These approaches are either costly, not as conducive to a high throughput platform, or may not detect novel Babesia pathogens [32, 33]. Screening diagnostic samples at the genus level using broad-range primers followed by additional analysis of PCR positive samples, such as species-specific PCRs and/or amplicon sequencing to determine the species, supports a high throughput platform, is cost effective, and facilitates the discovery of "new" pathogens. Identifying a DNA target conserved among Babesia that contains hypervariable sequences flanked by highly conserved sequences, 
Table 4 Retrospective analysis qPCR results. Retrospective qPCRs were performed simultaneously on previously characterized diagnostic or research samples from mammals that were uninfected $(n=4)$, naturally infected with Babesia or Cytauxzoon species $(n=31)$ or other vector-borne pathogens $(n=13)$

\begin{tabular}{|c|c|c|c|c|}
\hline \multirow[t]{2}{*}{ Characterized sample (source) } & \multicolumn{2}{|c|}{ Babesia 18S qPCR } & \multicolumn{2}{|c|}{ Babesia LSU qPCR } \\
\hline & $C_{q}$ & $\mathrm{~T}_{m}\left({ }^{\circ} \mathrm{C}\right)$ & $\mathrm{C}_{\mathrm{q}}$ & $\mathrm{T}_{m}\left({ }^{\circ} \mathrm{C}\right)$ \\
\hline B. bovis (cow) & 32.2 & 86.5 & 17.0 & 76.5 \\
\hline B. caballi (horse) & 29.4 & 86 & 29 & 77 \\
\hline B. caballi (horse) & 36.3 & 86 & 35.1 & 76.5 \\
\hline B. canis (dog) & 33.7 & 86 & 32.9 & 77 \\
\hline B. canis (dog) & 36.7 & 86 & 36.8 & 77 \\
\hline B. canis (dog) & 32.5 & 86 & 31.4 & 77 \\
\hline B. rossi (dog) & 23.7 & 86 & 22.8 & 76.5 \\
\hline B. vogeli (dog) & 21.9 & 86.5 & 20.5 & 77 \\
\hline B. vogeli (dog) & 21.1 & 86 & 17.8 & 76.5 \\
\hline B. coco (dog) & 34.7 & 86 & 27.8 & 77 \\
\hline B. coco (dog) & 32.1 & 86 & 25.1 & 77 \\
\hline B. coco (dog) & - & none & 40.6 & 77 \\
\hline B. conradae (dog) & 34.2 & 86 & 19.8 & 76 \\
\hline B. conradae (dog) & 39 & 86 & 19.7 & 76 \\
\hline B. conradae (dog) & - & none & 17.3 & 76 \\
\hline B. conradae (dog) & - & none & 21.4 & 76.5 \\
\hline B. gibsoni (dog) & 13.2 & 86 & 13.01 & 77 \\
\hline B. gibsoni (dog) & 19.3 & 86 & 19.2 & 77 \\
\hline B. lengau (leopard) & 38.2 & 85.5 & 18 & 76 \\
\hline B. microti-like (dog) & - & none & 30.8 & 77 \\
\hline B. microti-like (dog) & - & none & 40.3 & 76.5 \\
\hline B. microti-like (dog) & 32 & 86 & 24 & 76.5 \\
\hline B. microti-like (red fox) & 36.5 & 85.5 & 27.8 & 76 \\
\hline B. microti-like (grey fox) & 36.6 & 85.5 & 28.2 & 76 \\
\hline B. odocoilei (reindeer) & 16.5 & 86 & 23.9 & 77 \\
\hline B. odocoilei (reindeer) & 13.5 & 86.5 & 25.5 & 77 \\
\hline B. odocoilei (elk) & 24.9 & 86.5 & 35.6 & 76.5 \\
\hline B. (sensu stricto) (maned wolf) & 14.4 & 86 & 13.6 & 77 \\
\hline B. (sensu stricto) (bear) & 34.1 & 86 & 32.4 & 76.5 \\
\hline Cytauxzoon felis (cat) & 31.8 & 85.5 & 17.2 & 77.5 \\
\hline C. felis (cat) & 35.3 & 85.5 & 21.2 & 77.5 \\
\hline Uninfected gDNA (cat) & - & none & - & none \\
\hline Uninfected gDNA (cow) & - & none & - & none \\
\hline Uninfected gDNA (dog) & - & none & - & none \\
\hline Uninfected gDNA (horse) & - & none & - & none \\
\hline Anaplasma phagocytophilum (dog) & - & none & - & none \\
\hline A. platys (dog) & - & none & - & none \\
\hline Bartonella henselae (cat) & - & none & - & none \\
\hline Ehrlichia canis (dog) & - & none & - & none \\
\hline E. ewingii (dog) & - & none & - & none \\
\hline Hepatozoon canis (dog) & 39.0 & 85 & - & none \\
\hline
\end{tabular}


Table 4 Retrospective analysis qPCR results. Retrospective qPCRs were performed simultaneously on previously characterized diagnostic or research samples from mammals that were uninfected $(n=4)$, naturally infected with Babesia or Cytauxzoon species $(n=31)$ or other vector-borne pathogens $(n=13)$ (Continued)

\begin{tabular}{llllc}
\hline H. americanum (dog) & - & none & - & none \\
Leishmania infantum (dog) & - & none & - & none \\
Mycoplasma hemocanis (dog) & - & none & - & none \\
Neorickettsia risticii (culture) & - & none & - & none \\
Rickettsia rickettsii (dog) & - & none & - & none \\
Theileria equi (horse) & 38.9 & 86 & - & none \\
Trypanosoma cruzi (dog) & - & none & none \\
\hline
\end{tabular}

Abbreviations: $C_{q}$ quantification cycle, $T_{m}$ melting temperature; -, Babesia was not amplified

where primers do not amplify other eukaryotic DNA can be challenging. The LSU qPCR assay amplifies a region of DNA spanning two large ribosomal subunits, lsu5-lsu4, that is conserved among piroplasmida indicating it is less likely to be deleted or changed due to DNA rearrangements or mutations [26-28]. This study demonstrated an increased level of relative sensitivity and a broader range of Babesia spp. detection when the LSU qPCR was compared to an established molecular diagnostic assay. There was improved detection when

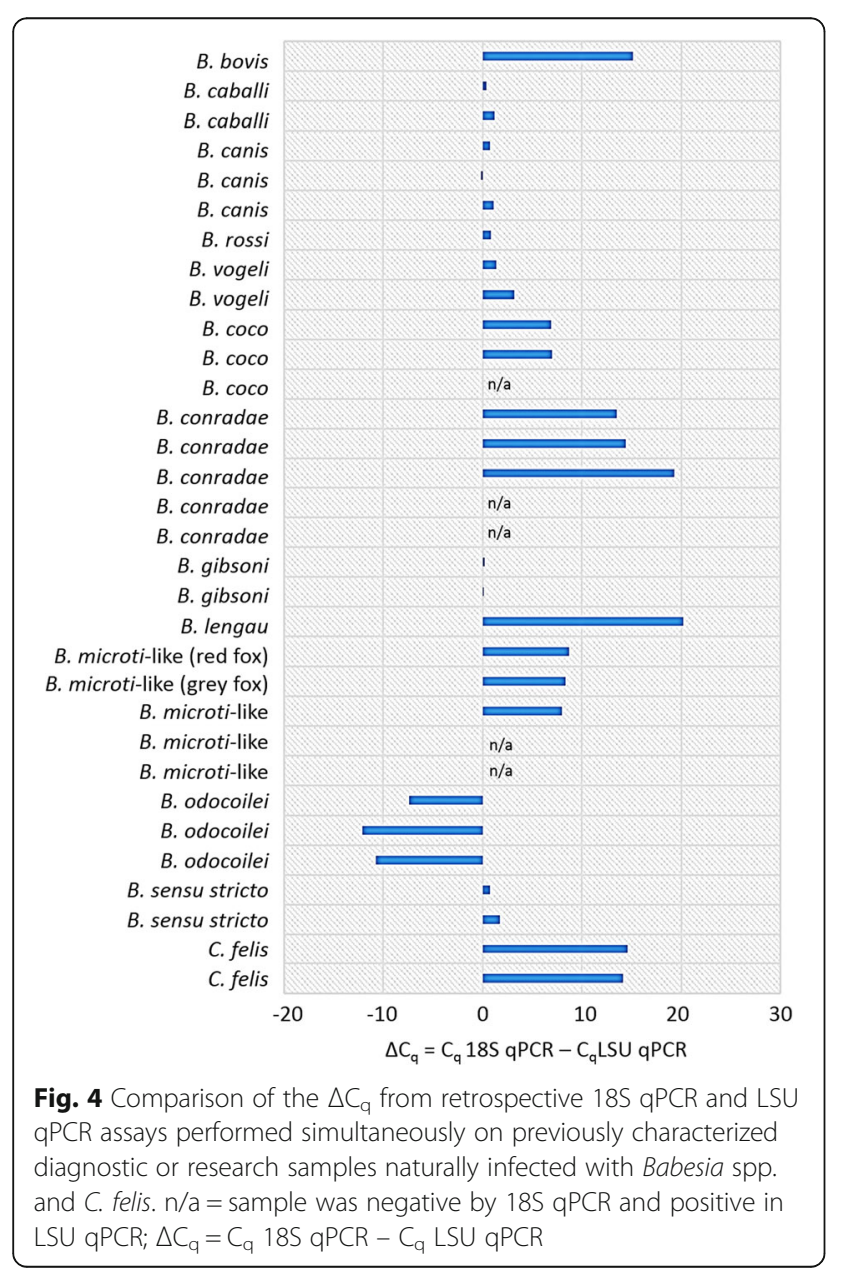

testing animal samples naturally infected with $B$. bovis, B. coco, B. conradae, B. lengau, and B. microti-like organisms. While we did not include a $C$. felis mtDNA sequence (GenBank accession no. KC207821) in the Babesia alignment used to design new primers, the Blsu-F and B-lsu-R2 primers are $100 \%$ identical to the corresponding sequences of the C. felis lsu5-lsu4 region and amplified this feline pathogen. For differentiation of C. felis from Babesia spp., the authors recommend either amplicon sequencing or testing the sample with a validated $C$. felis species-specific PCR [17].

The $\mathrm{C}_{\mathrm{q}}$ differences $\left(\Delta \mathrm{C}_{\mathrm{q}}=18 \mathrm{~S}\right.$ qPCR $\mathrm{C}_{\mathrm{q}}$ - LSU qPCR $\mathrm{C}_{\mathrm{q}}$ ) between the $18 \mathrm{~S} \mathrm{qPCR}$ and the LSU qPCR have several possible explanations (Table 1, Fig. 4). It is possible the noted differences were due in part to differing primer efficiencies and not necessarily related to target DNA copy number. Primer alignments using the $18 \mathrm{~S}$ qPCR primers, Bcommon-F $(\mathrm{bp}=24)$ and Bcommon- $\mathrm{R}$ $(\mathrm{bp}=29)$, revealed base pair mismatches were greatest with the Bcommon-F primer in B. conradae $(9 / 24) B$. lengau (8/24), B. microti-like (7/24), and C. felis (9/24), while all the other Babesia spp. in the retrospective sample set had bp mismatches $\leq$ five (Fig. 5). Except for $B$. microti and B. microti-like, where a different forward primer is used for the LSU qPCR target, the B-lsu-F primer has only two mismatches with $B$. canis and $B$. vogeli. However, these mismatches are mitigated with two degenerate primer nucleotides (Fig. 2). The B-lsu-R2

Table 5 Positive LSU qPCR results were compared with $18 \mathrm{~S}$ qPCR results from a prospective analysis performed on canine diagnostic samples naturally infected with Babesia spp.

\begin{tabular}{lll}
\hline Total samples $(n=394)$ & $18 S$ & LSU \\
\hline B. canis $(+)$ & 2 & 2 \\
B. vogeli $(+)$ & 2 & 2 \\
B. coco $(+)$ & 0 & 2 \\
B. gibsoni $(+)$ & 7 & 12 \\
B. microti-like $(+)$ & 0 & 1 \\
\% Positive $(95 \% \mathrm{Cl})$ & $2.8(1.1-4.4 \%)$ & $4.8(3.1-7.5 \%)$ \\
\hline
\end{tabular}

$(+)=C_{q}$ value obtained, $T_{m}$ value was correct 
Table 6 Prospective analysis was performed on canine diagnostic samples naturally infected with Babesia spp. and quantification cycles $\left(C_{q}\right)$ were compared between the 19 positive samples detected by Babesia genus assays (18S qPCR or LSU qPCR) and species-specific assays (18S sp-sp or cox1 sp-sp). Results are shown from the original Babesia genus qPCRs, discordant samples that were repeated in triplicate with the Babesia genus qPCRs, and Babesia species-specific qPCRs. All positive samples generated the correct melting temperature $\left(T_{m}\right)$ values (not shown)

\begin{tabular}{|c|c|c|c|c|c|c|}
\hline \multirow[b]{3}{*}{ Babesia spp. } & \multicolumn{4}{|c|}{ Genus level qPCR } & \multicolumn{2}{|c|}{ Species-specific qPCR } \\
\hline & \multicolumn{2}{|c|}{ Original results } & \multicolumn{2}{|c|}{ Repeated results (triplicate) } & \multirow[b]{2}{*}{$18 S$} & \multirow[b]{2}{*}{$\cos 1$} \\
\hline & $18 \mathrm{~S}$ & LSU & $18 \mathrm{~S}$ & LSU & & \\
\hline B. canis & 31.4 & 30.5 & na & na & 31.6 & 30.0 \\
\hline B. canis & 31.7 & 29.9 & na & na & 31.8 & 31.3 \\
\hline B. vogeli & 30.6 & 29.4 & na & na & 31.3 & 31.4 \\
\hline B. vogeli & 32.1 & 32.1 & na & na & 31.1 & 31.7 \\
\hline B. gibsoni & 13.8 & 13.9 & na & na & 14.8 & 16.3 \\
\hline B. gibsoni & 17.7 & 19.6 & na & na & 19.5 & 22.9 \\
\hline B. gibsoni & 19.6 & 18.0 & na & na & 21.8 & 24.4 \\
\hline B. gibsoni & 21.6 & 22.2 & na & na & 30.1 & 23.0 \\
\hline B. gibsoni & 29.2 & 30.4 & na & na & 29.2 & 30.8 \\
\hline B. gibsoni & 18.0 & 18.0 & na & na & 19.3 & 19.7 \\
\hline B. gibsoni & 13.5 & 13.3 & na & na & 14.5 & 15.8 \\
\hline B. coco & - & 39.8 & - & $38.5 ; 38.6 ; 33.8$ & - & 39.0 \\
\hline B. coco & - & 38.2 & - & $39.2 ; 33.1 ;-$ & - & 36.0 \\
\hline B. gibsoni & - & 37.5 & - & - & - & - \\
\hline B. gibsoni & - & 39.4 & - & $40.7 ; 38.3 ; 38.4$ & 39 & 37.0 \\
\hline B. gibsoni & - & 30.9 & - & $29.4 ; 29.7 ; 30.6$ & - & 31.1 \\
\hline B. gibsoni & - & 39.0 & 37.0; -; - & $38.4 ;-;-$ & - & 36.2 \\
\hline B. gibsoni & - & 38.4 & - & $39.5 ; 38.6 ;-$ & - & 39.0 \\
\hline B. microti-like & - & 29.0 & - & $31.0 ; 30.6 ; 30.3$ & 32 & na \\
\hline
\end{tabular}

Abbreviations: na, the sample was not retested; -, Babesia was not amplified

Table 7 Positive percent agreement (PPA) and negative percent agreement (NPA)

\begin{tabular}{llll}
\hline & Positive & Negative & Row sum \\
\hline LSU qPCR (index) $^{18 S}$ qPCR (non-reference standard) & \\
Positive $^{\text {a }}$ & 11 & 8 & 19 \\
Negative $^{\text {b }}$ & 0 & 375 & 375 \\
Column sum $^{11}$ & 11 & 383 & 394 \\
18S qPCR (index) & LSU qPCR (non-reference standard) & \\
Positive $^{c}$ & 11 & 0 & 11 \\
Negative $^{\text {d }}$ & 8 & 375 & 383 \\
Column sum & 19 & 375 & 394 \\
\hline
\end{tabular}

Note: We calculated PPA and NPA using $18 \mathrm{~S}$ qPCR assay (top) or LSU qPCR assay as the non-reference standard

${ }^{\mathrm{a} P P A}=100 \%(95 \% \mathrm{Cl}: 69.9-100 \%)$

${ }^{\mathrm{b}} \mathrm{NPA}=98 \%(95 \% \mathrm{Cl}: 95.9-99.0 \%)$

CPPA $=58 \%(95 \% \mathrm{Cl}: 36.2-76.9 \%)$

${ }^{\mathrm{d}} \mathrm{NPA}=100 \%$ (95\% Cl: $\left.98.8-100 \%\right)$ primer $(\mathrm{bp}=22)$ has no mismatches except one in $B$. divergens and two in B. microti and B. microti-like.

A large prospective set of samples from dogs suspected of exposure to vector-borne pathogens was used to measure relative sensitivity and specificity between an established diagnostic qPCR and a newly developed qPCR. The newly developed LSU qPCR relative sensitivity was $100 \%$ when compared to the established $18 \mathrm{~S}$ qPCR, while the $18 \mathrm{~S}$ qPCR relative sensitivity was 58\% when compared to the LSU qPCR, suggesting the new assay is more sensitive at detecting Babesia. The LOD for the LSU qPCR assay was determined to be $\sim$ five copies/reaction while the established Babesia 18S rDNA was determined to be between five and ten copies/reaction (data not included); both LODs were determined using plasmids containing one copy of the target DNA diluted in canine gDNA. Making direct comparisons between LODs with other qPCRs reported in the literature using similar methods of calculation show the LSU and $18 \mathrm{~S}$ qPCRs to be comparable. One assay targeting $B$. canis hsp70 calculated a LOD at $\sim$ ten copies using a probe for detection [12]; another qPCR assay targeting 


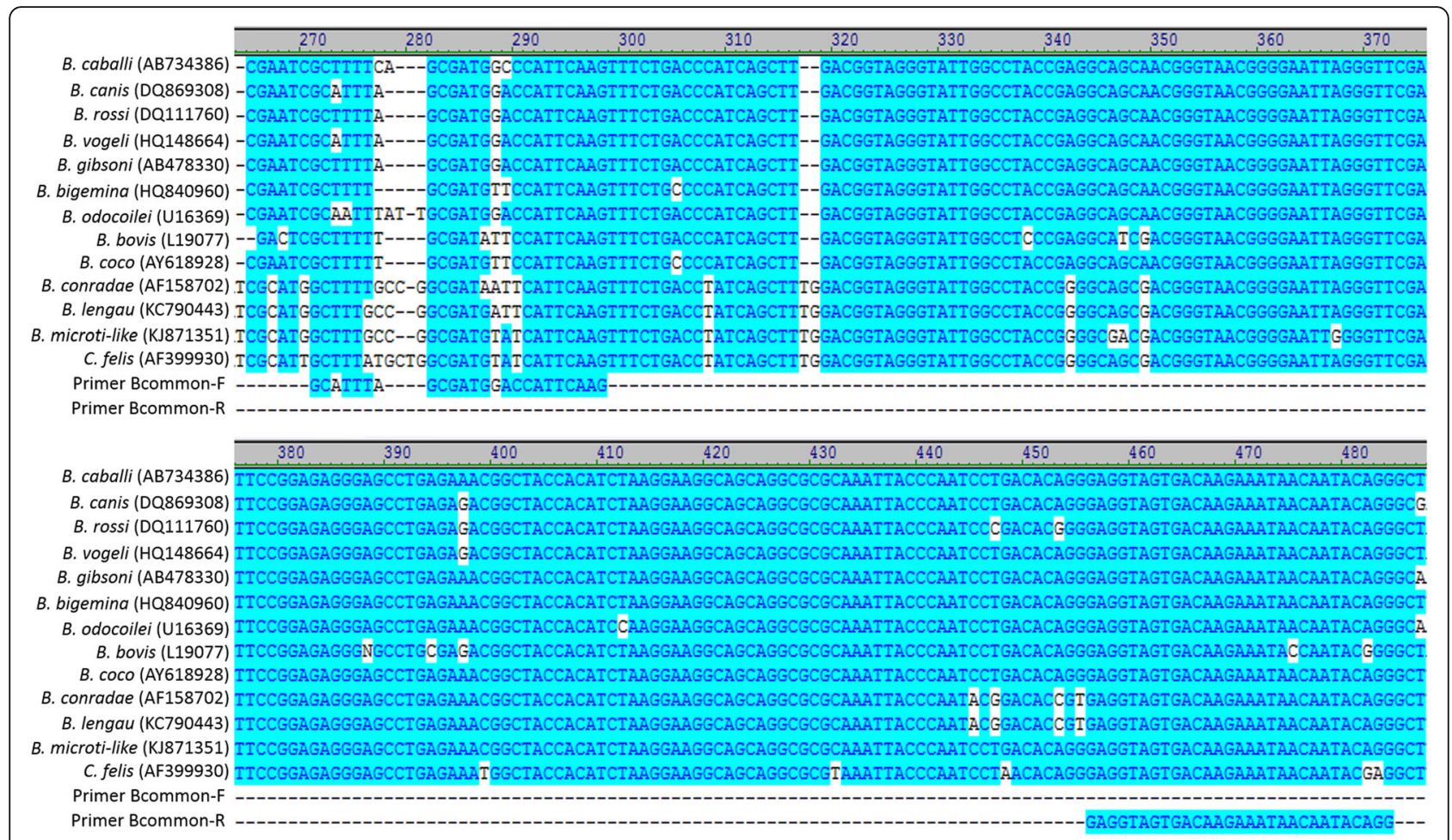

Fig. 5 Sequence alignment of the 18S rRNA gene from representative Babesia spp., Cytauxzoon felis and primers designed for use in the Babesia $18 \mathrm{~S}$ qPCR assay. The GenBank accession numbers are shown in parentheses

B. microti $18 \mathrm{~S}$ rDNA calculated $\sim 3.6$ copies per reaction using blood spiked with plasmid DNA [34]. Both the LSU and 18S qPCR assays had high specificities relative to each other, with the $98 \%$ specificity reported for LSU qPCR reflecting the positive discordant samples not detected by the $18 \mathrm{~S}$ qPCR.

When comparing results from naturally infected canine samples used for the prospective study, eight samples were PCR negative by the $18 \mathrm{~S}$ qPCR but positive by the LSU qPCR (Table 7). It is unclear if this difference in sensitivity is related to improved primer binding and subsequent amplification, increased target copy number, or clinical status of the patient at time of sampling (treated or untreated). It's possible mtDNA copy numbers vary among Babesia species or stages of piroplasmida infection. Schreeg et al. detected higher mtDNA copy numbers in cats acutely infected with $C$. felis when compared to cats infected over a year [17]. It remains unclear if there is a link between the mtDNA copy number and stage of Babesia infection.

Limitations of this study include the inability to calculate true sensitivity and specificity for the new LSU qPCR assay and that the new assay was only compared to one other qPCR assay. However, in both the prospective and retrospective sample sets, the LSU qPCR outperformed the $18 \mathrm{~S}$ qPCR. While reasons behind this improvement remain unclear, we hypothesis that increased target copy number for the mitochondrial PCR is a contributing factor.

\section{Conclusions}

In summary, we have developed a qPCR assay with increased sensitivity to detect a broader number of Babesia spp. The LSU qPCR targets a highly conserved region of the mtDNA spanning the lsu5-lsu4 region. Retrospective and prospective analysis with samples from naturally infected animals highlight the expansive range of Babesia spp. detection and improved relative sensitivity when compared to a current $18 \mathrm{~S}$ qPCR. Currently the VBDDL has implemented the new LSU qPCR assay for all diagnostic Babesia PCRs and confirms all positive samples with a second species-specific qPCR, targeting either the 18S rRNA or cox1 genes. Samples from ungulates are also screened with the $18 \mathrm{~S}$ qPCR for improved detection of B. odocoilei.

\section{Abbreviations}

18S qPCR: qPCR assay targeting a region of the 18 S rRNA gene in Babesia spp.; $C_{q}$ : Quantification cycle; EDTA: Ethylenediamine tetraacetic acid; gDNA: Genomic DNA; LSU qPCR: qPCR assay targeting a region of the large subunit rRNA gene fragments Isu5- Isu4 on the mtDNA of Babesia spp.; mtDNA: Mitochondrial DNA; NPA: Negative percent agreement; PPA: Positive percent agreement; qPCR: Quantitative real-time polymerase chain reaction; $\mathrm{T}_{m}$ : Melting temperature; VBDDL: Vector-Borne Disease Diagnostic Laboratory 


\section{Acknowledgments}

We thank the VBDDL and Intracellular Pathogens Research Laboratory for the use of animal whole-blood samples.

\section{Funding}

This research received no specific grant from any funding agency in the public, commercial, or not-for-profit sectors. Dr. Barbara Qurollo's vector-borne disease research at the College of Veterinary Medicine, North Carolina State University is partially supported by IDEXX Laboratories, Inc.

\section{Availability of data and materials}

Not applicable.

\section{Authors' contributions}

Study design, coordination and execution done by BAQ; Mitochondrial DNA arrangement and sequence information MES, HSM, AJB; Sample collection, characterization and donation HSM, MES, BST AJB, EEB. Molecular diagnostics were done by BAQ, NRA, KNH, and BST. All authors contributed to the content and approved the final manuscript.

\section{Competing interests}

Dr. Barbara Qurollo's vector-borne disease research at the College of Veterinary Medicine, North Carolina State University is partially supported by IDEXX Laboratories, Inc.

\section{Consent for publication}

Not applicable.

\section{Ethics approval and consent to participate}

All animal samples were submitted for diagnostic testing purposes through the VBDDL. All submission forms accompanying each sample for testing through the VBDDL contain the following disclosure: "All samples of sufficient volume are stored for potential future testing for a minimum of 2 years. We reserve the right to use archived samples for research purposes, always respecting privacy rights of the contributing animal, owner and veterinarian." Publication of this clinical data set from animals naturally infected with or exposed to vector-borne disease does not compromise anonymity or confidentiality or breach local data protection laws.

\section{Received: 12 October 2016 Accepted: 27 February 2017}

\section{Published online: 07 March 2017}

\section{References}

1. Patton WS. Preliminary report on a new piroplasm (Piroplasma gibsoni sp. nov.) found in the blood of the hounds of the Madras Hunt and subsequently discovered in the blood of the jackal Canis aureus. Bull Soc Pathol Exot. 1910;3:274-80.

2. Carret C, Walas F, Carcy B, Grande N, Précigout E, Moubri K, et al. Babesia canis, Babesia canis vogeli, Babesia canis rossi: differentiation of the three subspecies by a restriction fragment length polymorphism analysis on amplified small subunit ribosomal RNA genes. J Eukaryot Microbiol. 1999:46:298-303.

3. Conrad PA, Thomford J, Yamane I, Whiting J, Bosma L, Uno T, et al. Hemolytic anemia caused by Babesia gibsoni infection in dogs. J Am Vet Med Assoc. 1991;199:601-5.

4. Birkenheuer AJ, Neel J, Ruslander D, Levy MG, Breitschwerdt EB. Detection and molecular characterization of a novel large Babesia species in a dog. Vet Parasitol. 2004;124:151-60.

5. Kjemtrup AM, Wainwright K, Miller M, Penzhorn BL, Carreno RA. Babesia conradae sp. nov., a small canine Babesia identified in California. Vet Parasitol. 2006;138:103-11.

6. García AT. Piroplasma infection in dogs in northern Spain. Vet Parasitol. 2006;138:97-102.

7. Taboada J, Lobetti R. Babesiosis. In: Greene CE, editor. Infectious diseases of the dog and cat. 3rd ed. St. Louis: Saunders Elsevier; 2006. p. 722-36.

8. Birkenheuer AJ, Levy MG, Breitschwerdt EB. Development and evaluation of a seminested PCR for detection and differentiation of Babesia gibsoni (Asian genotype) and B. canis DNA in canine blood samples. J Clin Microbiol. 2003:41:4172-7.
9. Teal AE, Habura A, Ennis J, Keithly JS, Madison-Antenucci S. A new real time PCR assay for improved detection of the parasite Babesia microti. J Clin Microbiol. 2012;50:903-8.

10. Vascellari M, Ravagnan S, Carminato A, Cazzin S, Carli E, Da Rold G, et al. Exposure to vector-borne pathogens in candidate blood donor and freeroaming dogs of northeast Italy. Parasit Vectors. 2016;9:369.

11. Paparini A, Senanayake SN, Ryan UM, Irwin PJ. Molecular confirmation of the first autochthonous case of human babesiosis in Australia using a novel primer set for the beta-tubulin gene. Exp Parasitol. 2014;141:93-7.

12. Peleg $\mathrm{O}$, Baneth $\mathrm{G}$, Eyal $\mathrm{O}$, Inbar J, Harrus S. Multiplex real-time $\mathrm{gPCR}$ for the detection of Ehrlichia canis and Babesia canis vogeli. Vet Parasitol. 2010;173:292-9.

13. Matsuu A, Ono S, Ikadai H, Uchide T, Imamura S, Onuma M, et al. Development of a SYBR green real-time polymerase chain reaction assay for quantitative detection of Babesia gibsoni (Asian genotype) DNA. J Vet Diagn Invest. 2005;17:569-73.

14. Zahler M, Schein E, Rinder H, Gothe R. Characteristic genotypes discriminate between Babesia canis isolates of differing vector specificity and pathogenicity to dogs. Parasitol Res. 1998;84:544-8.

15. Kordick SK, Breitschwerdt EB, Hegarty BC, Southwick KL, Colitz CM, Hancock $\mathrm{SI}$, et al. Coinfection with multiple tick-borne pathogens in a Walker Hound kennel in North Carolina. J Clin Microbiol. 1999:37:2631-8.

16. Wilson RJ, Williamson DH. Extrachromosomal DNA in the Apicomplexa. Microbiol Mol Biol Rev. 1997:61:1-16.

17. Schreeg ME, Marr HS, Griffith EH, Tarigo JL, Bird DM, Reichard MV, et al. PCR amplification of a multi-copy mitochondrial gene (cox3) improves detection of Cytauxzoon felis infection as compared to a ribosomal gene (185). Vet Parasitol. 2016;225:123-30

18. Salem GH, Liu X, Johnsrude JD, Dame JB, Roman RG. Development and evaluation of an extra chromosomal DNA-based PCR test for diagnosing bovine babesiosis. Mol Cell Probes. 1999;13:107-13.

19. Bilgic HB, Karagenç T, Shiels B, Tait A, Eren H, Weir W. Evaluation of cytochrome $b$ as a sensitive target for PCR based detection of $T$. annulata carrier animals. Vet Parasitol. 2010;174:341-7.

20. Buling A, Criado-Fornelio A, Asenzo G, Benitez D, Barba-Carretero JC, FlorinChristensen M. A quantitative PCR assay for the detection and quantification of Babesia bovis and B. bigemina. Vet Parasitol. 2007;147:16-25.

21. Haanshuus CG, Mohn SC, Mørch K, Langeland N, Blomberg B, Hanevik K. A novel, single-amplification PCR targeting mitochondrial genome highly sensitive and specific in diagnosing malaria among returned travelers in Bergen, Norway. Malar J. 2013;12:26.

22. Isozumi R, Fukui M, Kaneko A, Chan CW, Kawamoto F, Kimura M. Improved detection of malaria cases in island settings of Vanuatu and Kenya by PCR that targets the Plasmodium mitochondrial cytochrome c oxidase III (cox3) gene. Parasitol Int. 2015;64:304-8.

23. Di Cicco MF, Downey ME, Beeler E, Marr H, Cyrog P, Kidd L, et al. Reemergence of Babesia conradae and effective treatment of infected dogs with atovaquone and azithromycin. Vet Parasitol. 2012;187:23-7.

24. Birkenheuer AJ, Horney B, Bailey M, Scott M, Sherbert B, Catto V, et al. Babesia microti-like infections are prevalent in North American foxes. Vet Parasitol. 2010;172:179-82.

25. Birkenheuer AJ, Correa MT, Levy MG, Breitschwerdt EB. Geographic distribution of babesiosis among dogs in the United States and association with dog bites: 150 cases (2000-2003). J Am Vet Med Assoc. 2005;227:942-7.

26. Hikosaka K, Watanabe Y, Tsuji N, Kita K, Kishine H, Arisue N, et al. Divergence of the mitochondrial genome structure in the apicomplexan parasites, Babesia and Theileria. Mol Biol Evol. 2010;27:1107-16.

27. Hikosaka K, Tsuji N, Watanabe Y, Kishine H, Horii T, Igarashi I, et al. Nove type of linear mitochondrial genomes with dual flip-flop inversion system in apicomplexan parasites Babesia microti and Babesia rodhaini. BMC Genomics. 2012;13:622.

28. Schreeg ME, Marr HS, Tarigo JL, Cohn LA, Bird DM, Scholl EH. t al. Mitochondrial genome sequences and structures aid in the resolution of Piroplasmida phylogeny. PLoS One. 2016;11(11):e0165702.02.

29. The Center for Devices and Radiological Health. Statistical guidance on reporting results from studies evaluating diagnostic tests. In: Guidance for Industry and FDA Staff. U.S. Food and Drug Administration. 2007. http:// www.fda.gov/RegulatoryInformation/Guidances/ucm071148.htm\#6. [Accessed 28 Feb 2017]

30. Feinstein AR, Cicchetti DV. High agreement but low kappa: I. The problems of two paradoxes. J Clin Epidemiol. 1990;43:543-9. 
31. Agresti A, Coull BA. Approximate is better than "exact" for interval estimation of binomial proportions. Am Stat. 1998:52:119-26.

32. Yisaschar-Mekuzas Y, Jaffe CL, Pastor J, Cardoso L, Baneth G. Identification of Babesia species infecting dogs using reverse line blot hybridization for six canine piroplasms, and evaluation of co-infection by other vector-borne pathogens. Vet Parasitol. 2013;191:367-73.

33. Jefferies R, Ryan UM, Irwin PJ. PCR-RFLP for the detection and differentiation of the canine piroplasm species and its use with filter paper-based technologies. Vet Parasitol. 2007;144:20-7.

34. Wang G, Wormser G, Zhuge J, Villafuerte, Ip D, Zeren C, Fallon J. Utilization of a real-time $P C R$ assay for diagnosis of Babesia microti-like infection in clinical practice. Ticks and Tick Borne Dis. 2015; 6:376-382

Submit your next manuscript to BioMed Central and we will help you at every step:

- We accept pre-submission inquiries

- Our selector tool helps you to find the most relevant journal

- We provide round the clock customer support

- Convenient online submission

- Thorough peer review

- Inclusion in PubMed and all major indexing services

- Maximum visibility for your research

Submit your manuscript at www.biomedcentral.com/submit
Biomed Central 